Cite this: RSC Advances, 2013, 3, 18164

Received 9th April 2013,

Accepted 9th July 2013

DOI: $10.1039 / c 3 r a 43090 a$

www.rsc.org/advances

\section{Synthesis and binding of proflavine diazides as functional intercalators for directed assembly on DNA $\dagger$}

\author{
Shahrbanou MoradpourHafshejani, ${ }^{a}$ Joseph H. Hedley, ${ }^{\text {ab }}$ Alexandra O. Haigh, ac \\ Andrew R. Pike ${ }^{\star a}$ and Eimer M. Tuite*a
}

Proflavine diazide (PD) with amido-azide substituents on the amine groups and its $N$-methylated analogue (MePD) bind strongly to DNA by nearest-neighbour intercalation with little sequence selectivity, presenting reactive azide groups in the major groove. PD is neutral in aqueous solution but experiences binding-coupled protonation on interaction with DNA with an apparent $\mathrm{p} K_{\mathrm{a}}$ shift of 2.5 units. MePD can be click modified in situ on DNA with alkyne-functionalised thienyl-pyrrole as a precursor for conducting polymer synthesis, and remains intercalated after reaction with the substituents aligned in the groove.

\section{Introduction}

The use of DNA as an architectural material was revolutionized by the seminal work of Seeman and coworkers in constructing 2D and 3D DNA nanostructures, ${ }^{1}$ which resulted in an explosion of research in this field. The exquisite specificity of nucleic acid recognition, together with chemical stability, has made DNA the polymer of choice for the construction of increasingly intricate nano-architectures. ${ }^{2}$ The DNA duplex is an attractive candidate as a 1D template or scaffold for assembly of functional materials via chemical reactions, coordination chemistry, or non-covalent association. ${ }^{3}$

Assembly of conducting polymers, e.g. polyaniline, ${ }^{4}$ polypyrrole and polythienylpyrrole ${ }^{5,6}$ on DNA has been a key area of interest for development of molecular wires. Control of polymerization can be achieved by tethering monomers to DNA on the bases, sugars, or modified backbones. ${ }^{7}$ Herein, we present first generation molecules for an alternative strategy which uses unmodified DNA as a scaffold to facilitate the linear assembly of functional materials. This strategy uses small molecules (ligands) that bind strongly to DNA with specific recognition modes (e.g. intercalation or groove binding $)^{8}$ to present reactive substituents in one DNA groove. Hence, the duplex becomes an adaptable scaffold without the requirement for chemical modification of DNA. Proflavine is the framework we have chosen initially for development of functional intercalators. ${ }^{9}$ The strong and well-characterized intercalative binding of acridines has led to their development as anticancer drugs, ${ }^{10}$ and these properties also make them attractive candidates for anchoring supramolecular architectures to a DNA scaffold.

Previously, 9-aminoacridine has been used as an intercalative ligand to assemble a copper catalyst on DNA for asymmetric synthesis, ${ }^{11}$ and proflavine has been modified with platinum complexes for improved therapeutics. ${ }^{12}$ Searcey and coworkers produced a library of substituted acridine intercalators using click chemistry in solution, ${ }^{13}$ one of which drove formation of Holliday junctions. ${ }^{13 b}$ 9-Aminoacridine azide was used for in situ click with an alkene peptide, where the reactants were pre-assembled. ${ }^{14 a}$ More recently, Balasubramanian and coworkers have used in situ click substitution of well-known tetraplex binders to identify drugs that bind selectively to G4 motifs. ${ }^{14 b}$ Also, minor groove binding azido-ligands have been used for assembly of functional molecules on AT-rich DNA. ${ }^{14 c}$ In this paper we report the synthesis of novel proflavine derivatives with amidoazide substituents that intercalate DNA and undergo in situ click reactions ${ }^{15}$ with molecules such as alkyne-substituted thienylpyrrole (TP). In this paper, we fully characterize their binding to DNA and in situ click reaction, and in related work ${ }^{5 f}$ we have shown that conducting poly $(\mathrm{TP})_{n}$ nanowires can be formed from the resultant assembly.

\section{Results}

\section{Synthesis and absorbance of diazido-proflavines}

Modification of proflavine (1, Pf) $\$$ with azide groups produces a ligand that presents "click" functionalities along DNA after intercalation. Initially, the exocyclic amines were converted to azides but that product was relatively unreactive. Thus, an 
<smiles>Nc1ccc2cc3ccc(N)cc3nc2c1</smiles>

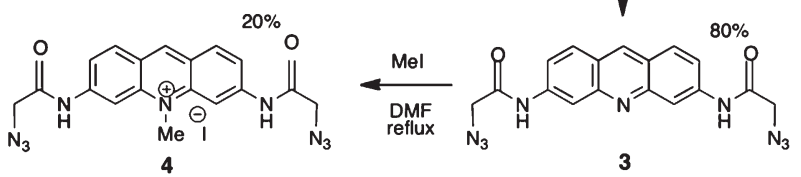

Scheme 1 Synthesis of azide-modified proflavines.

extended amide linker was introduced to increase accessibility of the azides, and overcome the reduced reactivity of $\mathrm{Pf}$ exocyclic amines after intercalation with DNA ${ }^{16}$ (Scheme 1).

Product 3 (proflavine diazide, PD) was obtained in good yield but proved poorly soluble in water, although it dissolved in polar solvents and in DNA solution. Consequently, methylated proflavine diazide (4, MePD) was synthesized, in which the ring nitrogen is quaternized to give a cationic species at $\mathrm{pH}$ 7. For direct comparison of $\mathbf{1}, \mathbf{3}$ and $\mathbf{4}$, all experiments were carried out in aqueous buffered solution containing $1 \%$ DMSO by volume. This allowed dissolution of PD to tens of millimolar and did not perturb the DNA conformation as judged by circular dichroism.

Aqueous solutions of Pf, PD, and MePD are yellow-orange due to absorbance in the $300-500 \mathrm{~nm}$ region (Fig. 1). The modified acridines absorb at higher energy with smaller extinction coefficients than Pf, as previously reported for spinlabelled Pf. ${ }^{17}$ All compounds also have significant absorbance in the $260 \mathrm{~nm}$ DNA region. Protonation on the ring nitrogen of Pf and PD is calculated to lower the energy of the absorption (supplementary informationt), consistent with observed shifts to longer wavelength of the absorption maxima at low $\mathrm{pH}$ (Table 1).

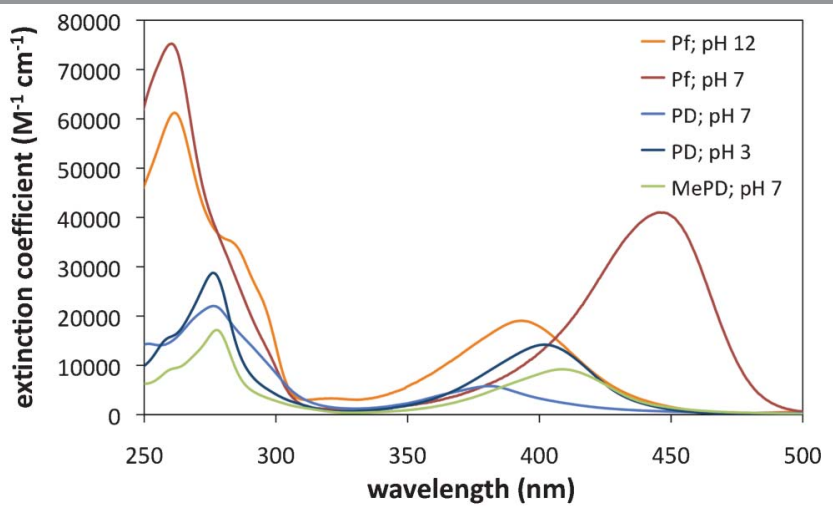

Fig. 1 Absorption spectra of the proflavine dyes in aqueous solution.

\footnotetext{
$\$$ Abbreviations: CD, circular dichroism; CT-DNA, calf thymus DNA; PD, proflavine diazide; Pf, proflavine; $\mathrm{LD}$, linear dichroism; $\mathrm{LD}^{\mathrm{r}}$, reduced linear dichroism; MePD, methylated proflavine diazide; $\mathrm{P} / \mathrm{D}$, nucleotide phosphate/dye ratio; $[\text { poly(dA-dT) }]_{2}$, poly(deoxyadenylic-thymidylic) acid; [poly(dG-dC) $]_{2}$, poly(deoxyguanylic-cytidylic) acid; TM, transition moment.
}

Table 1 Maximum wavelengths and extinction coefficients for absorption of the acridine dyes in the visible, and comparison with calculated energies for the HOMO-LUMO gap ${ }^{a}$

\begin{tabular}{lllll}
\hline Species & $\mathrm{pH}$ & $\lambda_{\text {max }} / \mathrm{nm}$ & $\varepsilon_{\text {max }} / \mathrm{M}^{-1} \mathrm{~cm}^{-1}$ & $\Delta E / \mathrm{eV}$ \\
\hline Pf & 12 & 393 & 19000 & 3.51 \\
$\mathrm{PfH}^{+}$ & 7 & 445 & 41000 & 3.29 \\
$\mathrm{PD}$ & 7 & 381 & 5800 & 3.62 \\
$\mathrm{PDH}^{+}$ & 3 & 403 & 13200 & 3.27 \\
$\mathrm{MePD}^{+}$ & 7 & 409 & 9200 & 3.35
\end{tabular}

${ }^{a} \lambda_{\max }$ and $\varepsilon_{\max }$, measured; $\Delta E$, calculated.

$\mathrm{p} K_{\mathrm{a}} \mathrm{s}$ for Pf in aqueous solution are reported at 0.3 and $9.5,{ }^{18}$ and our data (supplementary information†) concur. At $\mathrm{pH} 7$ the dominant monocation has an $\mathrm{S}_{0} \rightarrow \mathrm{S}_{1}$ absorption maximum at $445 \mathrm{~nm}$ with an extinction coefficient of 41000 $\mathrm{M}^{-1} \mathrm{~cm}^{-1} \cdot{ }^{19}$ At high $\mathrm{pH}$, deprotonation of the ring nitrogen produces the neutral form absorbing at higher energy $\left(\lambda_{\max }=\right.$ $393 \mathrm{~nm}$ ) with a smaller extinction efficient. The spectra of the di- and tri-cationic forms $(\mathrm{pH}<0)$, for further protonation on the exocyclic nitrogens, are reported to have maxima at 350$360 \mathrm{~nm}$ and extinction coefficients comparable to the neutral species. ${ }^{18,20} \mathrm{MePD}$ is also monocationic at $\mathrm{pH} 7$ with a $\mathrm{p} K_{\mathrm{a}}$ of 9.6 for deprotonation. The poor aqueous solubility of PD is consistent with a dominant neutral form at $\mathrm{pH} 7$, which renders the compound very hydrophobic. As $\mathrm{pH}$ drops from 9 to 1 , the PD spectrum changes substantially with an isosbestic point at $365 \mathrm{~nm}$ (Fig. 2a). A p $K_{\mathrm{a}}$ is observed at $\mathrm{pH} \sim 4.4$, and is assigned to protonation of the ring nitrogen.

Partial charges calculated for the neutral and monocation forms of PD, Pf, and MePD (supplementary informationt) explain the change of $\mathrm{p} K_{\mathrm{a}}$ when Pf carries amido-azide substituents. For neutral Pf, the ring nitrogen carries a high negative partial charge with partial positive charges on the exocyclic amines, and the charge density changes significantly after protonation of the ring nitrogen. For neutral PD, the negative charge on the ring nitrogen is much smaller due to significant negative charge density on the amide linker and azide nitrogens. After protonation of the ring nitrogen, the

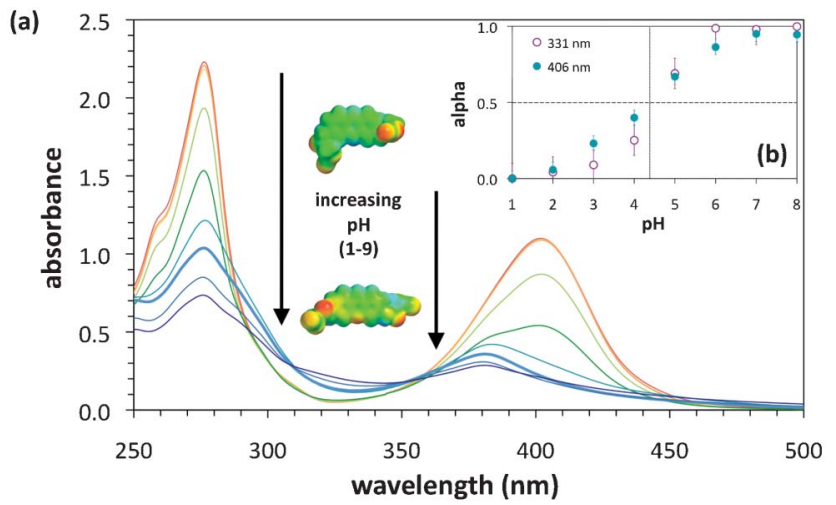

Fig. 2 Effect of pH on the absorption spectrum of PD. (a) spectra and calculated partial charges, and ( $b$, inset) titration, $[\mathrm{PD}]=54 \mu \mathrm{M}$. 


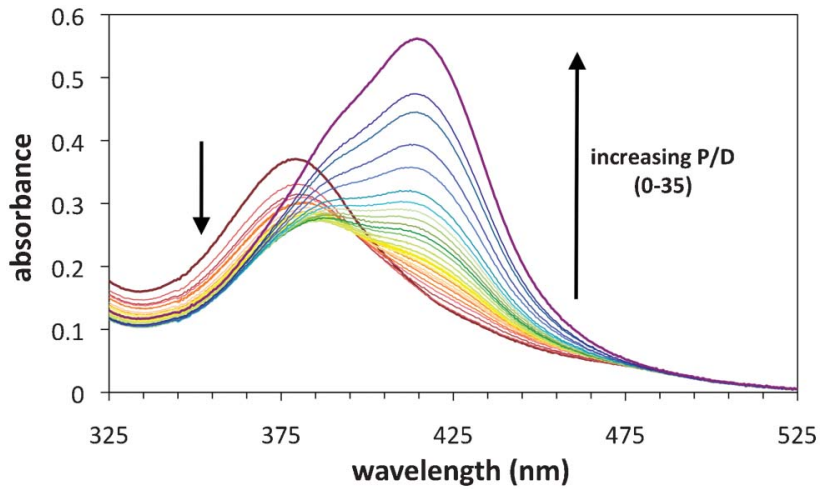

Fig. 3 Effect of binding to calf thymus(CT)-DNA on the absorption spectrum of PD. The spectrum without DNA is shown in dark red. P/D is the DNA (nucleotide phosphate) to dye ratio. [PD] $=56 \mu \mathrm{M}$.

negative charges remain localized on the amido-azide substituents. Cationic MePD has a similar partial charge distribution to PD monocation.

\section{Interaction of diazido-proflavines with DNA}

Absorption spectroscopy. The binding of Pf, MePD and PD to calf thymus (CT) DNA is readily observed by monitoring visible absorbance. ${ }^{21}$ For $\mathrm{Pf}$ and MePD, addition of DNA results in red-shifts of $\sim 15 \mathrm{~nm}$ and hypochromicity. This is typical of the effects of insertion between DNA basepairs during intercalation, a binding mode previously shown for Pf.

For PD, a dramatically different behaviour is observed (Fig. 3). A $35 \mathrm{~nm}$ red-shift is accompanied by a hyperchromism of $>50 \%$. Although this apparently indicates a different mode of binding, it is actually consistent with intercalation where binding is coupled to protonation. The maximum absorption of the DNA-bound dye at $416 \mathrm{~nm}$ represents a $13 \mathrm{~nm}$ shift from the maximum of $\mathrm{PDH}^{+}$. Additionally, the large absorbance increase compared to the $\mathrm{PD}$ spectrum represents a hypochromic change compared to the spectrum of free $\mathrm{PDH}^{+}$. Thus, the changes in PD absorbance on addition of DNA can be rationally interpreted in terms of the dominant DNA-bound species being the monocationic $\mathrm{PDH}^{+}$.

Coupled protonation and DNA binding has been reported previously for neutral dibenzoacridine ${ }^{22 a}$ as well as other intercalators, ${ }^{22 b}$ minor groove binders ${ }^{22 c}$ and proteins. ${ }^{22 d}$ It is also known that the apparent $\mathrm{p} K_{\mathrm{a}}$ of cytosine is raised significantly from $\sim 4.5$ when it protonates on formation of CGC-triplexes, with a 3-5 unit increase reported for internal positions. $^{23}$ Moreover theory predicts that the DNA minor groove is more acidic than the surrounding solvent, ${ }^{24 a}$ with experiments indicating a drop of up to 2 units. $^{24 b}$ This is likely a result of the high negative potential in the minor groove caused by electrostatic focussing. ${ }^{25}$ Thus, the increase of apparent $\mathrm{p} K_{\mathrm{a}}$ of $\mathrm{PD}$ on binding to DNA is not without precedent.

Absorption changes were analysed by the Scatchard method to obtain binding constants and apparent site sizes as shown in Table 2. Proflavine binds very strongly to CT-DNA and only a lower limit for the association constant could be determined at
Table 2 Association constants (K) and apparent binding site sizes ( $n$ ) for the modified proflavine dyes with calf thymus (CT)-DNA ${ }^{a}$

\begin{tabular}{llcl}
\hline Dye & {$\left[\mathrm{Na}^{+}\right] / \mathrm{mM}$} & $\mathrm{K} / \mathrm{M}^{-1}$ & $\mathrm{n}^{b}$ \\
\hline Pf & 7.5 & $\geqslant 3.8 \times 10^{6}$ & 0.26 \\
Pf & 508 & $1.4 \times 10^{5}$ & 0.28 \\
PD & 7.5 & $5.3 \times 10^{5}$ & 0.33 \\
MePD & 7.5 & $2.0 \times 10^{6}$ & 0.36
\end{tabular}

${ }^{a}$ Determined by absorption titration in $5 \mathrm{mM}$ phosphate-1\% DMSO;

${ }^{b} \mathrm{n}=$ number of binding sites per nucleotide unit.

low ionic strength. As the salt concentration was raised, binding weakened and an association constant was readily determined with $500 \mathrm{mM} \mathrm{NaCl}$ added to buffer. The binding constant in $5 \mathrm{mM}$ phosphate was estimated theoretically using Record/Manning theory, which states that $\mathrm{K}$ for a monocationic intercalator varies with added inert monocation according to eqn (1), with $B=0.24, Z=1$, and $\Psi=0.82^{26}$ or $1 .{ }^{27}$

$$
\frac{\mathrm{d}\left(\ln K_{\mathrm{obs}}\right)}{\mathrm{d}\left(\ln \left[\mathrm{Na}^{+}\right]\right)}=-(B+Z \psi)
$$

A binding constant of $\mathrm{K} \approx 1.5 \times 10^{7} \mathrm{M}^{-1}$ was predicted at $7.5 \mathrm{mM} \mathrm{Na}^{+}$, which is higher than the experimental value, and represents an upper limit at low ionic strength. The binding constants measured for Pf have similar magnitudes to previously reported values. ${ }^{28,29} \mathrm{PD}$ and MePD also show high affinities for DNA, with site sizes that are close to nearestneighbour, although their binding constants are lower than that for Pf. Nonetheless, at low ionic strength, both PD and MePD are quantitatively bound to DNA at high ratios of DNA basepair to dye concentrations, expressed as P/D ([nucleotide phosphate]/[dye]).

Circular dichroism spectroscopy. Pf, PD and MePD are achiral in aqueous solution. On binding to DNA, all three exhibit small induced circular dichroism (ICD) signals in their visible absorption bands (Fig. 4). ICD occurs when an achiral molecule is placed in a chiral environment, e.g., when a dye is

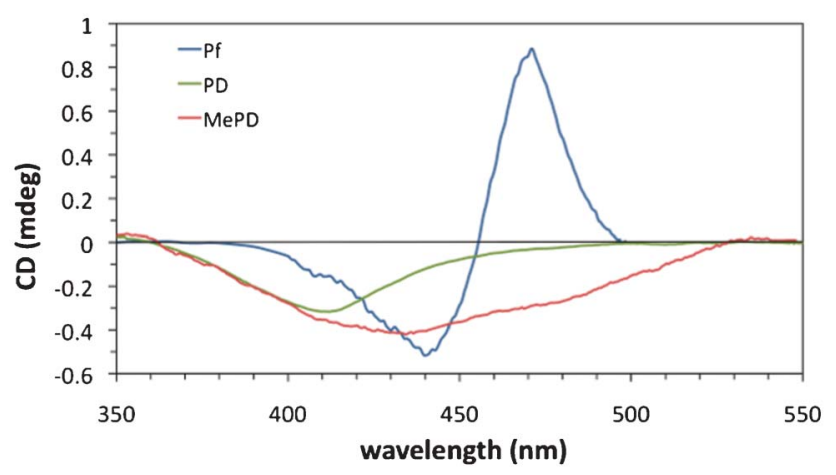

Fig. $4 C D$ spectra in the visible region showing induced $C D$ of the dyes in the presence of calf thymus (CT)-DNA. [Pf] $=10 \mu \mathrm{M}, \mathrm{P} / \mathrm{D}=50 ;[\mathrm{PD}]=50 \mu \mathrm{M}, \mathrm{P} / \mathrm{D}=$ 20; $[\mathrm{MePD}]=50 \mu \mathrm{M}, \mathrm{P} / \mathrm{D}=10 . \mathrm{P} / \mathrm{D}$ is the DNA (nucleotide phosphate) to dye ratio. Data are smoothed (see supplementary informationt for raw data). 
bound to the right-handed helix of DNA. ${ }^{30}$ The ICD signals are weak, consistent with intercalative binding. ${ }^{31}$

The ICD for Pf resembles that reported previously for similar binding ratios at low ionic strength in native DNA, [poly(dA$\mathrm{dT})]_{2}$, and $[\mathrm{poly}(\mathrm{dG}-\mathrm{dC})]_{2} \cdot{ }^{29,32-34}$ The non-conservative splitting pattern has been attributed to degenerate vibronic exciton coupling between intercalated and externally bound dyes. ${ }^{28 c, 34}$ External binding is found to be minimal at high salt concentrations but to occur to some extent at low salt concentrations even at the high $\mathrm{P} / \mathrm{D}$ ratios used in this work. ${ }^{34,35}$ The deconvoluted CD spectrum of pure intercalated $\mathrm{Pf}$ is reported to be positive but that of acridine orange, which is tetramethylated on the exocyclic nitrogens, is negative. ${ }^{34}$ This was attributed to different intercalation geometries of the two dyes, since the transition moment involved is the same long-axis polarized $\pi-\pi^{*}$ transition for each. ${ }^{34-36}$ It was suggested that H-bonds between Pf and the DNA backbone, as observed in crystal structures, are responsible for that difference since the magnitude of the Pf ICD was sensitive to increasing ionic strength. Negative ICD spectra for PD and MePD suggest that these dyes might have intercalation orientations more similar to acridine orange than Pf; indeed, small slides or twists of the dye in the intercalation pocket can cause a sign inversion. ${ }^{37}$ The absence of splitting in the ICD spectra of PD and MePD suggests that external binding is less important for these dyes than for Pf, perhaps because the increased bulk of the side chains hinders association of additional dyes in the groove as observed when Pf external binding is blocked by glycosylation of the major groove in T2DNA. $^{32}$

Linear dichroism spectroscopy. In flow linear dichroism (LD) spectroscopy, high molecular weight DNA is oriented by shear flow in a Couette cell. ${ }^{30} \mathrm{LD}$ is defined by eqn (2), where $A_{\text {iso }}$ is the isotropic absorption of the sample (i.e., without orientation), $S$ is an orientation factor, and $\alpha$ represents the angle between the polarization of the absorbing transition moment and the orientation axis.

$$
\operatorname{LD}^{\mathrm{r}}(\lambda)=\operatorname{LD}(\lambda) / A_{\text {iso }}(\lambda)=1.5 S\left(3\left\langle\cos ^{2} \alpha\right\rangle-1\right)
$$

The LD signal of DNA is negative in the 200-350 nm absorption region, where the strongly absorbing transition moments (TM) are polarized in the planes of the basepairs. Since the helix axis of aligned DNA is oriented parallel to the flow direction, negative LD indicates that the basepairs are oriented more perpendicular than parallel to the helical axis, as expected for B-form DNA. For all three acridines, the LD signals in the visible spectrum are also negative (supplementary informationt). This implies that the TMs responsible for visible absorption, which are polarized in the acridine aromatic planes, ${ }^{34,36}$ also have an average orientation $>54^{\circ}$ to the helix axis.

For structural interpretation of LD, reduced linear dichroism (LD ${ }^{r}$ ) spectra were computed (Fig. 5) using eqn (2). In general, the $\mathrm{LD}^{\mathrm{r}}$ signals at $260 \mathrm{~nm}$ for DNA with and without dye report on changes in base orientation induced by dye binding, although overlap of strong dye absorption with DNA at $260 \mathrm{~nm}$ precludes quantitative analysis. The ratio of $\mathrm{LD}^{\mathrm{r}}$ signals in the visible and UV regions allows calculation of the
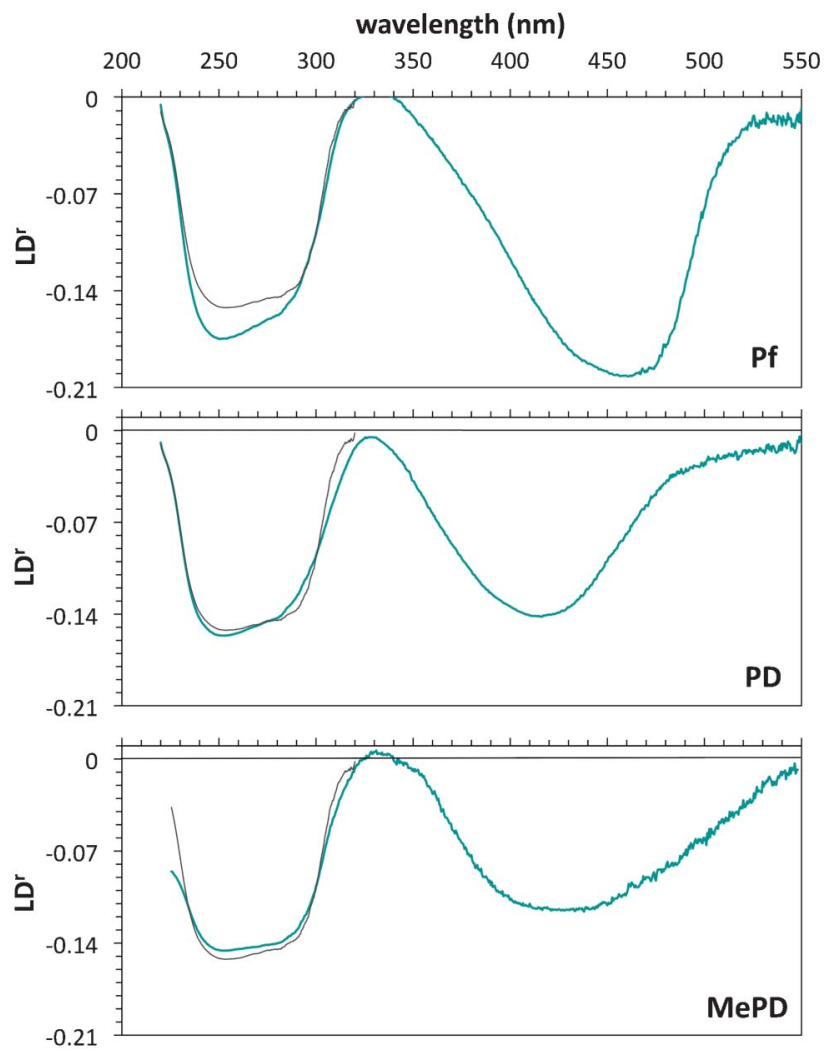

Fig. 5 Reduced linear dichroism (LDr) spectra of acridine dyes with calf thymus (CT)-DNA. P/D = 50; [DNA] = $1 \mathrm{mM}$. Shear gradient $=1900 \mathrm{~s}^{-1}(600 \mathrm{rpm})$. $P / D$ is the DNA (nucleotide phosphate) to dye ratio. The free DNA spectrum is shown in grey.

angle between the dye and base pair planes. An important caveat is that the latter comparison is valid only if all the dye absorption arises from bound material, since free dye contributes to isotropic absorption but not to LD. Therefore, spectra were measured under conditions (low salt and high $\mathrm{P} / \mathrm{D}$ ) that favour complete binding. For our samples, there was good correspondence between the isotropic absorption and LD spectra, showing close to $100 \%$ of dye is bound.

Negative $\mathrm{LD}^{\mathrm{r}}$ signals in the dye visible absorption bands (Fig. 5) are consistent with the chromophore long axes lying approximately parallel to the base pair planes. For Pf, this agrees with previous electric LD results which showed the ring system was parallel to the base planes for DNA with various base compositions. ${ }^{38}$ Pf shows greater magnitude $\mathrm{LD}^{\mathrm{r}}$ in the visible than in the UV. For $\mathrm{PD}$ and $\mathrm{MePD}$, the visible $\mathrm{LD}^{\mathrm{r}}$ magnitude is lower than that in the UV. Previous studies have inferred an effective value of $80-86^{\circ}$ for the orientation of the basepairs to the helix axis. ${ }^{29,39}$ Nevertheless, significantly more negative $\mathrm{LD}^{\mathrm{r}}$ in the dye than the DNA band, as observed for Pf, has also been reported for other intercalators such as methylene blue. ${ }^{37 c, d}$ Previous spectral analysis ${ }^{36}$ of $\mathrm{Pf}$ and related dyes assigned the $465 \mathrm{~nm}$ absorption solely to a longaxis polarized transition, and $263 \mathrm{~nm}$ absorption predominantly to long-axis polarized transitions with a small contribution from a short-axis polarized transition. Similar assignments are likely for PD and MePD. Thus different 


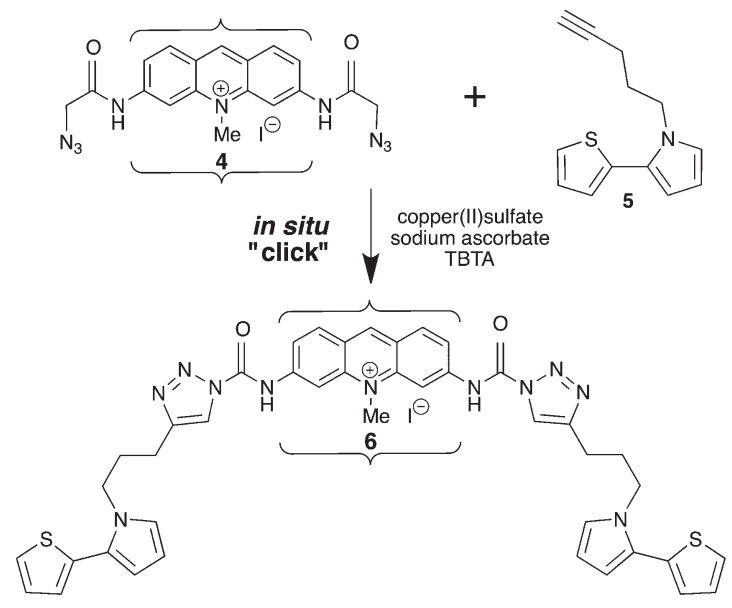

Scheme 2 In situ "click" reaction of MePD (4) and PTP (5) to generate MePDpTP (6). Brackets represent the intercalation site in DNA. Arrows represent presumed main transition moment directions.

values of $\mathrm{LD}^{\mathrm{r}}(\mathrm{vis}) / \mathrm{LD}^{\mathrm{r}}(\mathrm{UV})$ suggest that $\mathrm{PD}$ and MePD adopt slightly different intercalation geometries than Pf, as also inferred from CD spectra. Wedging intercalation from the major groove, due to the bulky substituents impeding full insertion between the basepairs, would result in smaller $\mathrm{LD}^{\mathrm{r}}$ for the dye since the chromophore would sample a range of orientation, as observed for piperazinecarbonyloxyalkyl derivatives of anthracene and pyrene. ${ }^{40}$

Linear dichroism spectroscopy shows that the ring systems of PD and MePD remain intercalated in DNA after their azide groups undergo click reactions (Scheme 2) with 5-pentenylthienyl-pyrrole (pTP). On the other hand, 6 formed in solution did not bind strongly to DNA. Thus, an in situ click reaction is necessary to assemble such a molecule on DNA.

At high dye loading (Fig. 6), the $\mathrm{LD}^{\mathrm{r}}$ signal at $425 \mathrm{~nm}$ in the MePD absorption band remains negative after the click reaction. A new negative signal is observed in the 300-350 $\mathrm{nm}$ region, where MePD has no contribution, which corresponds to absorption of the pTP substituent (supplementary informationt). The absorbing transition moment of the clicked TP chromophore thus has an average orientation of $<54^{\circ}$ to

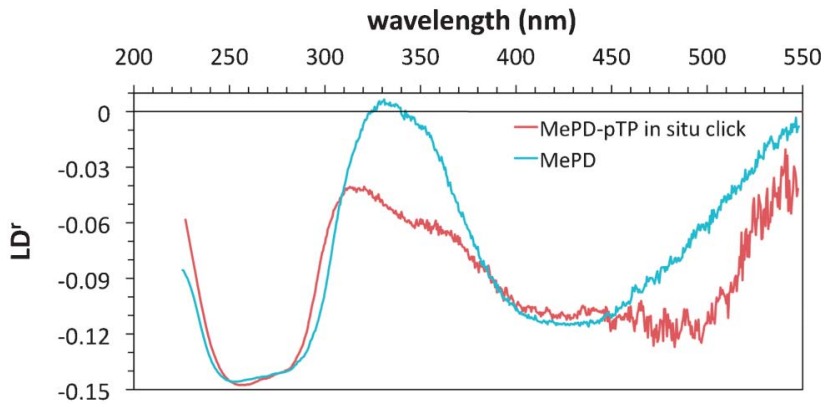

Fig. 6 Reduced linear dichroism (LD') spectrum of in situ generated MePD-pTP (6) bound to calf thymus (CT)-DNA compared with DNA-bound MePD. ${ }^{5 f} \mathrm{P} / \mathrm{D}=$ 50; $[D N A]=1 \mathrm{mM}$. P/D is the DNA (nucleotide phosphate) to dye ratio. Shear gradient $=3170 \mathrm{~s}^{-1}(1000 \mathrm{rpm})$.

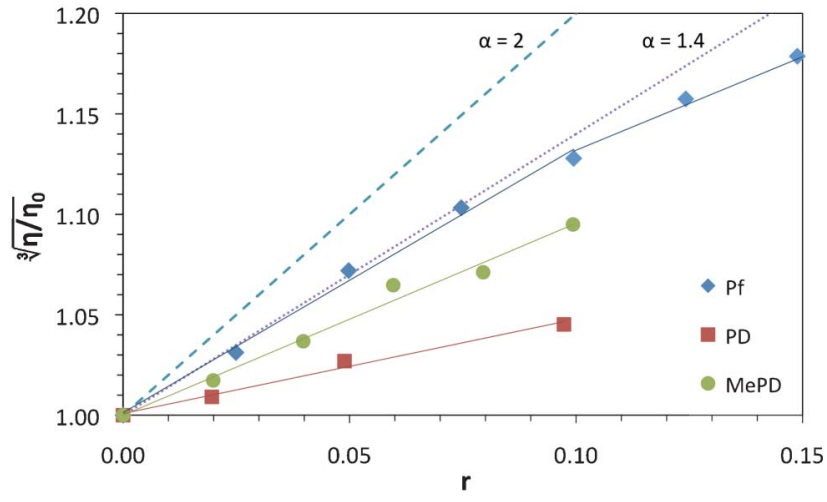

Fig. 7 Relative intrinsic viscosity of calf thymus (CT)-DNA on addition of acridine dyes. [DNA] $=300 \mu \mathrm{M} ; 25^{\circ} \mathrm{C}$.

the helix axis. If we set the DNA basepair $(260 \mathrm{~nm})$ orientation at $90^{\circ}$ to the helix axis, the calculated angles are $74^{\circ}$ for MePD $(425 \mathrm{~nm})$ and $63^{\circ}$ for pTP $(350 \mathrm{~nm})$. By contrast, at low dye loading (supplementary informationt), the $\mathrm{LD}^{\mathrm{r}}$ signal at $300-$ $350 \mathrm{~nm}$ is positive whilst the signal in the PD absorption band at $430 \mathrm{~nm}$ remains negative, and the angle for pTP substituents in this case is calculated as $52^{\circ}$. Thus, the proximity of nearest neighbour intercalated PD forces the TP residues into an orientation somewhat more parallel to the basepairs. Nonetheless, the TP residues can polymerise into long conducting poly $(\mathrm{TP})_{n}$ nanowires from this orientation, as we have demonstrated elsewhere..$^{5 f}$

Viscometry. Binding of proflavine increases DNA viscosity (Fig. 7), as expected for a classical intercalator, and consistent with previous reports. ${ }^{29,41,42}$ Studies with different DNAs found greater apparent elongation for AT-rich than GC-rich DNA, ${ }^{42,43}$ due to Pf having a greater tendency to bind externally with the latter and distort the binding ratio. Fig. 7 shows that PD and MePD also increase the viscosity of CT-DNA, but to a lesser extent. Pf is quantitatively bound under the conditions used, and the initial slope of 1.40 (up to $\mathrm{r}=0.1$ ) is consistent with monointercalation into high molecular weight DNA with no significant change of persistence length (supplementary informationt). An absence of persistence length change on bisintercalation of YOYO-1 has been reported. ${ }^{44}$

PD and MePD are also quantitatively bound, and although their slopes (0.99 and 0.50, respectively) are lower than for Pf, they are consistent with intercalation. The slope for PD is substantially lower than for Pf or MePD, and its low value implies either that some bound PD is externally associated, or that binding causes a reduction in persistence length that counteracts the increase in contour length due to intercalation. However, the lack of splitting in $\mathrm{CD}$ spectroscopy indicates that external binding is not important for PD and MePD, certainly not to the extent of $50 \%$ being externally bound.

Minor groove binders cause little change in viscosity ${ }^{45}$ but partial intercalators decrease DNA viscosity by bending through wedging, ${ }^{46}$ whilst covalent binding of cisplatin decreases DNA viscosity through static bending. ${ }^{47}$ These bending interactions decrease the viscosity of rod-like DNA 
by shortening the axial length. In long DNA, the bending effect is translated to a decrease of persistence length, which reduces the relative viscosity according to eqn (3). Since MePD and PD still increase viscosity, albeit less so than Pf, they cannot be considered to behave as true partial intercalators that bind by wedging open the basepairs toward one groove. Nonetheless, the results suggest that they adopt an intercalation geometry that reduces DNA persistence length.

$$
\sqrt[3]{\frac{[\eta]}{[\eta]_{0}}}=\frac{\mathrm{L}}{\mathrm{L}_{0}}=1+\alpha \mathrm{r}
$$

Thermal denaturation. Each dye increases the thermal stability of CT-DNA (supplementary informationt), as previously reported for Pf. $^{19 a, 29}$ The degree of stabilization correlates with binding affinity, so that $\mathrm{Pf}$ has a slightly larger effect than MePD, which in turn has a much larger effect than PD. The greater stabilizing effect of Pf compared to MePD is more dramatic at $\mathrm{P} / \mathrm{D}=1$, suggesting that $\mathrm{Pf}$ has greater tendency for electrostatically-driven external binding at high loading and low ionic strength than does MePD, as also inferred from CD. Similar results were observed with [poly(dA$\mathrm{dT})]_{2}$ but comparative experiments with $[\text { poly }(\mathrm{dG}-\mathrm{dC})]_{2}$ were impossible because of the high melting temperature $\left(95^{\circ} \mathrm{C}\right)$ observed for the naked polynucleotide, so that addition of dye raised the $\mathrm{T}_{\mathrm{m}}$ to $>100{ }^{\circ} \mathrm{C}$.

Fluorescence. The emission of all three acridines is quenched on binding to calf-thymus DNA, as shown in Fig. 8. For Pf, as for related dyes, ${ }^{48}$ this is attributed to electron transfer from guanine to the dye singlet state. ${ }^{28 a, 49}$ Our observations that the emission intensity of Pf bound to CT-DNA decreases in the range $\mathrm{P} / \mathrm{D}=0-20$ and thereafter slowly rises (Fig. 8), mirrors previously reported behaviour. ${ }^{49}$ Pf emission is quenched by guanine but enhanced by adenine from comparison of emission in the presence of $[\text { poly }(\mathrm{dA}-\mathrm{dT})]_{2}$ and $[p o l y(d G-d C)]_{2}$. The quenching observed at low $\mathrm{P} / \mathrm{D}$ with [poly(dA-dT) $]_{2}$ is attributed to self-quenching by externally stacked dyes, ${ }^{21,28 c, 35}$ and at high binding ratios the intensity reflects the increase in reported lifetime. ${ }^{41}$

Both $\mathrm{PD}$ and $\mathrm{MePD}^{+}$are quenched by adenine as well as guanine in polynucleotides, indicating that their singlet states are more readily reduced than ${ }^{1} \mathrm{Pf}$. Ground state reduction is predicted to occur more readily than for Pf due to lower electron densities on their aromatic ring systems, and their $(0,0)$ transitions are at higher energy than that of Pf. Taken together, these features rationalize why the excited singlet states of PD and MePD are significantly more oxidizing than that of Pf. Emission titrations indicate that PD and MePD show little selectivity in binding to $[\mathrm{poly}(\mathrm{dA}-\mathrm{dT})]_{2}$, [poly(dG$\mathrm{dC})]_{2}$ or mixed sequence CT-DNA. Pf binds most strongly to $[\text { poly }(\mathrm{dG}-\mathrm{dC})]_{2}$ under our conditions, other studies report little selectivity at higher ionic strength. ${ }^{29}$ However, recent molecular modelling ${ }^{50}$ suggests that Pf should indeed bind more strongly to $[\mathrm{poly}(\mathrm{dG}-\mathrm{dC})]_{2}$ than $[\mathrm{poly}(\mathrm{dA}-\mathrm{dT})]_{2}$ due to greater $\pi-\pi$ stacking in the former case. We interpret our observations in terms of the smaller substituents on Pf allowing it to intercalate deeply into the base pair pockets, thus benefiting from enhanced $\pi-\pi$ stacking in the GC pockets. By contrast, if

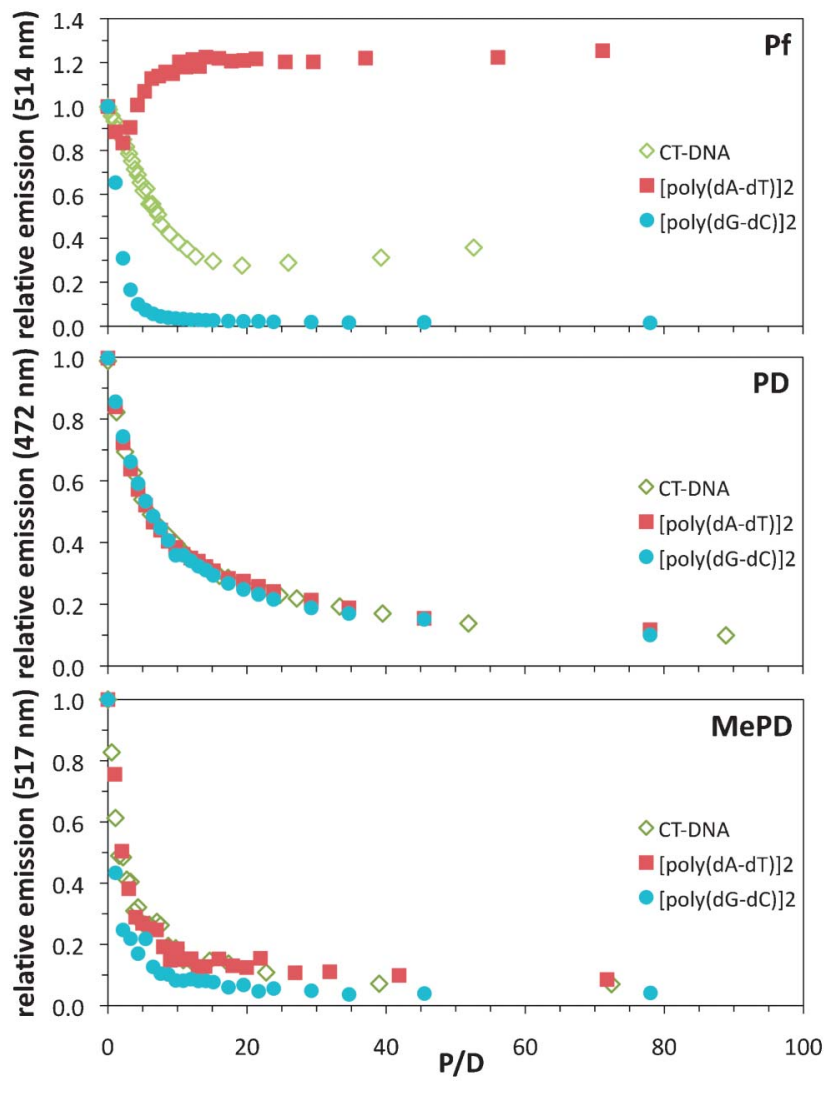

Fig. 8 Variation of emission intensity of acridine dyes on addition of calf thymus (CT)-DNA and alternating homopolynucleotides. P/D is the DNA (nucleotide phosphate) to dye ratio. [dye] $=5 \mu \mathrm{M}$.

PD and MePD cannot intercalate as deeply as Pf from the major groove due to their bulky substituents, they will experience similar stacking interactions in all types of base pair pockets.

\section{Discussion}

Linear dichroism and viscometry results demonstrate that Pf, PD and MePD intercalate between the DNA base pairs. The small induced CD signals are also consistent with intercalative binding. Other results such as absorption, emission, and thermal denaturation titrations reflect the relative binding affinities of the three compounds. Proflavine was chosen as the framework molecule for our functional intercalators since it known to be an avid intercalator. A recent PDB deposition $(3 \mathrm{FT} 6)^{51 a}$ shows a crystal structure of proflavine intercalated at terminal CG/CG steps in a hexamer duplex (supplementary informationt). The heterocyclic system is deeply intercalated and the exocyclic amino groups are both oriented towards the major groove but do not protrude. Symmetric intercalation with the dye long axis parallel to the base pair long axis allows the amines to form $\mathrm{H}$-bonds with the phosphate and sugar groups of the backbone. This crystal structure confirms an earlier $\mathrm{nmr}$ structure with a tetramer $[\mathrm{d}(\mathrm{CCGG})]_{2},{ }^{51 b}$ and 
crystal structures with $\mathrm{RNA}^{51 c}$ and $\mathrm{DNA}^{51 d, e}$ CG dinucleotide minihelices. By comparison, $N, N^{\prime}$-tetramethyl proflavine (or acridine orange, $\mathrm{AO}$ ) and $\mathrm{N}$-dimethyl proflavine are intercalated asymmerically in dinucleotide minihelix crystals with $\sim 10^{\circ}$ twist from the symmetric geometry. ${ }^{52}$ These dyes are slightly displaced towards the major groove in the basepair pocket, with one dimethyl amine group protruding and the other amine in a position similar to Pf. This small change of conformation is enough to cause a change in ICD signal from positive for Pf to negative for AO. ${ }^{34}$ Given the negative ICD spectra for PD and MePD bound to DNA, a reasonable hypothesis is that they adopt an intercalation geometry similar to AO, displaced towards the major groove, but likely with both their bulky azide substituents protruding. The wide major groove should readily accommodate these substituents and present them for reaction with molecules approaching from bulk solution.

Such variation of intercalation geometry also rationalises differences in LD and viscosimetry for different dyes. Partial intercalators with small aromatic groups strongly reduce the viscosity of DNA. ${ }^{46 a}$ However, although PD and MePD give lower slopes than Pf, they nevertheless markedly increase DNA viscosity. Likewise, the $\mathrm{LD}^{\mathrm{r}}$ signals for these compounds are still strongly negative, although smaller than for Pf. Taken together, these observations suggest that PD and MePD bind by intercalation with slightly different geometries and dynamics than Pf, since their bulky substituents probably prevent the aromatic tricycle from embedding deeply in the intercalation pocket. Instead, they may be displaced towards the edges of the basepairs closest to the major groove which could give rise to dynamic or static bending of DNA, as seen for the partial intercalator $\left[\mathrm{Ru}(\mathrm{phen})_{3}\right]^{2+466,53}$ or for covalently bound cisplatin. ${ }^{47}$ Smaller $\mathrm{LD}^{\mathrm{r}}$ signals for the modified dyes are consistent with this postulate, since partially intercalated dyes can explore a range of orientation angles other than perpendicular to the helix axis. ${ }^{40}$ Consequently, PD and MePD show little sequence selectivity which is advantageous for their general application as versatile intercalative anchors for directed assembly on a DNA scaffold.

\section{Conclusions}

Proflavine, Pf, can be readily modified with azide groups on its exocyclic amines via an amide linker. The resultant compound, PD, is neutral but methylation on the ring nitrogen gives a cationic dye, MePD. PD is poorly soluble in water, but becomes protonated on binding to DNA, resulting in an apparent $\mathrm{p} K_{\mathrm{a}}$ shift of $>3$ units. Like proflavine, PD and MePD intercalate DNA, as evidenced by linear dichroism and viscometry. The Pf exocyclic amines reside in the major groove of DNA, and it is likely that the modified dyes adopt a similar binding geometry. However, their larger substituents appear to hinder deep intercalation, implying displacement towards the edge of the major groove, as reported for acridine orange, so that the basepairs become slightly wedged apart to reduce the
DNA persistence length. DNA-bound PD and MePD undergo in situ click functionalization with pTP, and remain intercalated after reaction thus placing the monomers in the major groove ready for polymerization to form a conducting chain. In summary, PD and MePD are good candidates for application as an intercalative anchor for assembly of supramolecular structures on a DNA scaffold since they bind strongly with little sequence selectivity, and remain intercalated after click reactions with bulky functional groups.

\section{Experimental}

All chemicals and solvents were of the highest grade available from Sigma-Aldrich. Proflavine hemisulfate salt hydrate was used as received, and proflavine derivatives were synthesized (Scheme 1) and purified as described in the supplementary information. $\dagger$ To ensure complete dissolution of dyes, solids were initially dissolved in $100 \%$ DMSO, and diluted with $5 \mathrm{mM}$ phosphate buffer with the required $\mathrm{pH}$ to give samples in 5 $\mathrm{mM}$ phosphate with 1\% DMSO. Polynucleotides [poly(dG$\mathrm{dC})]_{2}$ and $[\operatorname{poly}(\mathrm{dA}-\mathrm{dT})]_{2}$, and high molecular weight calfthymus DNA were from Sigma. All nucleic acids were dialyzed extensively against pure water before use to remove excess salts, and were stored in $5 \mathrm{mM}$ sodium phosphate buffer $(\mathrm{pH}$ 6.9). All experiments were carried out in $5 \mathrm{mM}$ phosphate buffer $/ 1 \%$ DMSO $(\mathrm{v} / \mathrm{v})$ at $21{ }^{\circ} \mathrm{C}$, unless otherwise stated, which allowed dissolution of PD to tens of millimolar. Although 10\% DMSO can distort binding of ligands, ${ }^{54} 1 \%$ DMSO did not perturb the DNA conformation as judged by circular dichroism, and binding results for Pf were consistent with those reported in the absence of DMSO. The concentrations of all materials were determined by UV/vis absorption spectroscopy using the following extinction coefficients, determined analytically for PD and MePD and obtained from the literature for the other materials. Pf (445 nm) $41000 \mathrm{M}^{-1} \mathrm{~cm}^{-1} ; ;^{19} \mathrm{PD}(381$ $\mathrm{nm}) 6600 \mathrm{M}^{-1} \mathrm{~cm}^{-1}$; MePD (409 nm) $9200 \mathrm{M}^{-1} \mathrm{~cm}^{-1}$; CT-DNA $(260 \mathrm{~nm}) 6600 \mathrm{M}^{-1} \mathrm{~cm}^{-1}$; [poly $\left.(\mathrm{dA}-\mathrm{dT})\right]_{2}(262 \mathrm{~nm}) 6700 \mathrm{M}^{-1}$ $\mathrm{cm}^{-1}$; [poly $\left.(\mathrm{dG}-\mathrm{dC})\right]_{2}(254 \mathrm{~nm}) 8400 \mathrm{M}^{-1} \mathrm{~cm}^{-1}$. Nucleic acid concentrations are given per nucleotide. Buffer of required $\mathrm{pH}$ was prepared by adjusting the $\mathrm{pH}$ of a $5 \mathrm{mM}$ phosphate $(\mathrm{pH}$ 6.9) solution using small aliquots of concentrated phosphoric acid or sodium hydroxide.

$\mathrm{UV} / \mathrm{vis}$ spectra and thermal denaturation were measuring with a Cary 100 Bio UV-visible spectrophotometer, and all data are normalized to a $1 \mathrm{~cm}$ pathlength. Titrations with calf thymus DNA solution were performed by adding aliquots of concentrated DNA to a constant concentration of ligand. Corrected fluorescence emission and excitation spectra were measured with a SPEX FluoroMax spectrophotometer. CD spectra were measured on a Jasco J-810 spectropolarimeter, and data were normalized to a $1 \mathrm{~cm}$ pathlength. The data are presented, as collected, in mdeg; these data can be converted to absorbance units through division by 32980 mdeg. LD spectra were measured on an Applied Photophysics Chirascan $\mathrm{CD}$ spectropolarimeter, adapted to produce linearly polarized 
light. Orientation of the intercalator nucleic acid samples was achieved in a flow Couette cell with an outer rotating cylinder and an inner cylinder of $3 \mathrm{~cm}$ diameter. The experimental path length was $1 \mathrm{~mm}$, and data are normalized to a $1 \mathrm{~cm}$ path length.

Molecular modelling was performed with Spartan 04 (Wavefunction) using the semi-empirical PM3 method and density functional (DFT) method B3LYP/6-31G* to calculate potential densities and HOMO and LUMO energies of Pf, PD, MePD and their protonated forms.

A Cannon-Manning extra low charge size 75 semi-micro viscometer, immersed in a water bath thermostated at $25{ }^{\circ} \mathrm{C}$, was used to measure the relative intrinsic viscosity ${ }^{55}$ of dilute solutions of CT-DNA. The DNA concentration and the viscometer volume $(300 \mathrm{~mL})$ were kept constant for a series of added dye concentrations. The flow time for water was $177 \mathrm{~s}$, and for solutions containing DNA was >245 s. Measurements were carried out in triplicate and gave standard deviations of $< \pm 1$ s. For long DNA, if the persistence length does not change on intercalation, a plot of the cube root of the relative intrinsic viscosity against binding ratio yields a slope of 1.4 (supplementary informationt). ${ }^{56}$

\section{Acknowledgements}

We express our gratitude to the Nuffield Foundation for supporting a high school summer studentship for $\mathrm{AOH}$, to COST D35 for networking opportunities, and to Newcastle University School of Chemistry for financial support.

\section{References}

1 (a) J. Chen and N. C. Seeman, Nature, 1991, 350, 631; (b) E. Winfree, F. Liu, L. A. Wenzler and N. C. Seeman, Nature, 1998, 394, 539.

2 (a) N. C. Seeman, Nature, 2003, 421, 427; (b) P. W. K. Rothemund, Nature, 2006, 440, 297-302; (c) A. V. Pinheiro, D. Han, W. M. Shih and H. Yan, Nat. Nanotechnol., 2011, 6, 763; (d) T. J. Bandy, A. Brewer, J. R. Burns, G. Marth, T. Nguyen and E. Stultz, Chem. Soc. Rev., 2011, 40, 138-148.

3 (a) E. Meggers, P. L. Holland, W. B. Tolman, F. E. Romesberg and P. G. Schultz, J. Am. Chem. Soc., 2000, 122, 10714; (b) G. H. Clever, K. Kaul and T. Carell, Angew. Chem., Int. Ed., 2007, 46, 6226; (c) S. Liu, G. H. Clever, Y. Takezawa, M. Kaneko, K. Tanaka, X. Guo and M. Shionoyo, Angew. Chem., Int. Ed., 2011, 50, 8886; (d) I. Bouamaied, T. Nguyen, T. Ruhl and E. Stultz, Org. Biomol. Chem., 2008, 6, 3888; (e) F. Menacher and H.A. Wagenknecht, Photochem. Photobiol. Sci., 2011, 10, 1275.

4 (a) P. Nickels, W. U. Dittmer, S. Beyer, J. P. Kotthaus and F. C. Simmel, Nanotechnology, 2004, 15, 1524; (b) B. Datta, G. B. Schuster, A. McCook, S. C. Harvey and K. Kakrzewska, J. Am. Chem. Soc., 2006, 128, 14428.

5 (a) A. R. Pike, S. N. Patole, N. C. Murray, T. Ilyas, B. A. Connolly, B. R. Horrocks and A. Houlton, Adv. Mater.,
2003, 15, 254; (b) S. A. F. Al-Said, R. Hassanien, J. Hannant, M. A. Galindo, S. Pruneanu, A. R. Pike, A. Houlton and B. Horrocks, Electrochem. Commun., 2009, 11, 550; (c) J. Hannant, J. H. Hedley, J. Pate, A. Walli, S. A. F. Al-Said, M. A. Galindo, B. A. Connolly, B. R. Horrocks, A. Houlton and A. R. Pike, Chem. Commun., 2010, 46, 5870; (d) M. A. Galindo, J. Hannant, R. W. Harrington, W. Clegg, B. R. Horrocks, A. R. Pike and A. Houlton, Org. Biomol. Chem., 2011, 9, 1555; (e) A. Mishchenko, M. Abdualla, A. Rudnev, Y. Fu, A. R. Pike and T. Wandlowski, Chem. Commun., 2011, 47, 9807; (f) S. MoradpourHafshejani, S. M. D. Watson, E. Tuite and A. R. Pike, Chem. Sci., 2013, under review; $(g)$ D. Erts, U. Malinovskis, I. Muiznieks and E. Tuite, Thin Solid Films, 2008, 516, 8969.

6 (a) W. Chen, G. Güler, E. Kuruvilla, G. B. Schuster, H.C. Chiu and E. Riedo, Macromolecules, 2010, 43, 4032; (b) Z. Ma, W. Chen and G. B. Schuster, Chem. Mater., 2012, 24, 3916-3922; (c) W. Chen and G. B. Schuster, J. Am. Chem. Soc., 2012, 134, 840-843.

7 (a) A. Houlton, A. R. Pike, M. A. Galindo and B. R. Horrocks, Chem. Commun., 2009, 1797; (b) Rajesh, T. Ahuja and D. Kumar, Sens. Actuators, B, 2009, 136, 275.

8 Nucleic Acids in Chemistry and Biology, ed. G. M. Blackburn, M. J. Gait, D. Loakes and D. M. Williams, RSC Publishing, Cambridge, 3rd edn, 2006.

9 (a) L. S. Lerman, J. Mol. Biol., 1961, 3, 18; (b) V. Luzzati, F. Masson and L. S. Lerman, J. Mol. Biol., 1961, 3, 634; (c) W. D. Sasikala and A. Mukherjee, Phys. Chem. Chem. Phys., 2013, 15, 6446.

10 W. A. Denny, Curr. Med. Chem., 2002, 9, 1655.

11 (a) G. Roelfes and B. L. Feringa, Angew. Chem., Int. Ed., 2005, 44, 3230; (b) A. J. Boersma, R. P. Megens, B. L. Feringa and G. Roelfes, Chem. Soc. Rev., 2010, 39, 2083.

12 (a) E. Ceci, R. Cini, A. Karaulov, M. B. Hursthouse, L. Maresca and G. Natile, J. Chem. Soc., Dalton Trans., 1993, 2491; (b) S. Biagini, A. Bianchi, T. Biver, A. Boggioni, I. V. Nikolayenko, F. Secco and M. Venturini, J. Inorg. Biochem., 2011, 105, 558.

13 (a) L. A. Howell, A. Howman, M. A. O'Connell, A. Mueller and M. Searcey, Bioorg. Med. Chem. Lett., 2009, 19, 5880; (b) L. A. Howell, Z. A. E. Walker, R. Bowater, M. O'Connell and M. Searcey, Chem. Commun., 2011, 47, 8262.

14 (a) S. Imoto, T. Hirohama and F. Nagatsugi, Bioorg. Med. Chem. Lett., 2008, 18, 5560; (b) M. Di Antonio, G. Biffi, A. Mariani, E.-A. Raiber, R. Rodriguez and S. Balasubramanian, Angew. Chem., Int. Ed., 2012, 51, 11073; (c) M. I. Sánchez, O. Vázquez, J. Martínez-Costas, M. E. Vázquez and J. L. Mascareñas, Chem. Sci., 2012, 3, 2383.

15 (a) H. C. Kolb, M. G. Finn and K. B. Sharpless, Angew. Chem., Int. Ed., 2001, 40, 2004; (b) C. R. Becer, R. Hoogenboom and U. S. Schubert, Angew. Chem., Int. Ed., 2009, 48, 4900; (c) A. H. El-Sagheer and T. Brown, Chem. Soc. Rev., 2010, 39, 1388; (d) A. H. El-Sagheer and T. Brown, Acc. Chem. Res., 2012, 45, 1258.

16 L. S. Lerman, J. Mol. Biol., 1964, 10, 367.

17 K. Yamaoka, S. Noji and M. Yoshida, Bull. Chem. Soc. Jpn., 1981, 54, 31.

18 S. G. Schulman, D. V. Naik, A. C. Capomacchia and T. Roy, J. Pharm. Sci., 1975, 64, 982. 
19 (a) N. F. Gersch and D. O. Jordan, J. Mol. Biol., 1965, 13, 138; (b) G. R. Haugen and W. H. Melhuish, Trans. Faraday Soc., 1964, 60, 386.

20 N. Mataga, Y. Kaifu and M. Koizumi, Bull. Chem. Soc. Jpn., 1956, 29, 373.

21 (a) A. R. Peacocke and J. N. H. Skerrett, Trans. Faraday Soc., 1956, 52, 261; (b) E. Tuite and J. M. Kelly, Biopolymers, 1995, $35,419$.

22 (a) J. Booth and E. Boyland, Biochim. Biophys. Acta, 1953, 12, 75; (b) F. Pierard, A. Del Guerzo, A. Kirsch-De Mesmaeker, M. Demeunynck and J. Lhomme, Phys. Chem. Chem. Phys., 2001, 3, 2911; (c) B. Njuyen, J. Stanek and W. D. Wilson, Biophys. J., 2006, 90, 1319; (d) F. M. Dullweber, T. Stubbs, J. Musil, J. Sturzebecher and G. Klebe, J. Mol. Biol., 2001, 313, 593.

23 (a) W. D. Wilson, H. P. Hopkins, S. Mizan, D. D. Hamilton and G. Zon, J. Am. Chem. Soc., 1994, 116, 3607; (b) J. L. Asensio, A. N. Lane, J. Dhesi, S. Bergqvist and T. Brown, J. Mol. Biol., 1998, 275, 811.

24 (a) G. Lamm and G. R. Pack, Proc. Natl. Acad. Sci. U. S. A., 1990, 87, 9033; (b) S. Hanlon, L. Wong and G. R. Pack, Biophys. J., 1997, 72, 291.

25 R. Rohs, A. M. West, A. Sosinsky, P. Liu, R. S. Mann and B. Honig, Nature, 2009, 461, 1248.

26 (a) M. T. Record, C. F. Anderson and T. M. Lohman, Q. Rev. Biophys., 1978, 11, 103; (b) W. D. Wilson and I. G. Lopp, Biopolymers, 1984, 23, 3025.

27 (a) G. S. Manning, Quart. Rev. Biophys., 1978, 11, 179; (b) R. A. G. Friedmann and G. S. Manning, Biopolymers, 1984, 23, 2671.

28 (a) J. C. Thomes, G. Weill and M. Daune, Biopolymers, 1969, 8, 647; (b) F. Quadrifoglio, V. Crescenzi and V. Giancotti, Biophys. Chem., 1974, 1, 319; (c) R. W. Armstrong, T. Kurucsev and U. P. Strauss, J. Am. Chem. Soc., 1970, 92, 3174.

29 B. García, J. M. Leal, R. Ruiz, T. Biver, F. Secco and M. Venturini, J. Phys. Chem. B, 2010, 114, 8555.

30 B. Nordén, A. Rodger and T. Dafforn, Linear Dichroism and Circular Dichroism: A Textbook on Polarized Light Spectroscopy, RSC Publishing, Cambridge, 2010.

31 R. Lyng, T. Härd and B. Nordén, Biopolymers, 1987, 26, 1327.

32 H. J. Li and D. M. Crothers, Biopolymers, 1969, 8, 217.

33 M. Kamiya, Biochim. Biophys. Acta, 1979, 562, 70.

34 D. Fornasiero and T. Kurucsev, J. Phys. Chem., 1981, 85, 613.

35 H. J. Li and D. M. Crothers, J. Mol. Biol., 1969, 39, 461.

36 Y. Matsuoka and K. Yamaoka, Bull. Chem. Soc. Jpn., 1979, 52, 3163.

37 (a) R. Lyng, A. Rodger and B. Nordén, Biopolymers, 1991, 31, 1709; (b) R. Lyng, A. Rodger and B. Nordén, Biopolymers, 1992, 32, 1201; (c) E. Tuite and B. Nordén, J. Am. Chem.
Soc., 1994, 116, 7548; (d) E. Tuite and B. Nordén, Chem. Comm., 1995, 53-54.

38 J. Ramstein, C. Houssier and M. Leng, Biochim. Biophys. Acta, 1973, 335, 54.

39 (a) Y. Matsuoka and B. Nordén, Biopolymers, 1982, 21, 2433; (b) P. J. Chou and J. Johnson, J. Am. Chem. Soc., 1993, 115, 1205.

40 H.-C. Becker and B. Nordén, J. Am. Chem. Soc., 2000, 122, 8344.

41 G. Cohen and H. K. Eisenberg, Biopolymers, 1969, 8, 45.

42 J. Ramstein, M. Dourlent and M. Leng, Biochem. Biophys. Res. Comm., 1972, 47, 874.

43 J. Ramstein, M. Ehrenberg and R. Rigler, Biochemistry, 1980, 19, 3938.

44 K. Günther, M. Mertig and R. Seidel, Nucl. Acids Res., 2010, 38, 6526.

45 D. Suh and J. B. Chaires, Bioorg. Med. Chem., 1995, 3, 723.

46 (a) L. Kapiak and E. J. Gabbay, J. Am. Chem. Soc., 1975, 97, 403; (b) S. Satyanarayana, J. C. Dabrowiak and J. B. Chaires, Biochemistry, 1992, 31, 9319.

47 J.-L. Butour and J.-P. Macquet, Biochim. Biophys. Acta, 1981, 653, 305.

48 (a) E. Tuite, J. M. Kelly, G. S. Beddard and G. D. Reid, Chem. Phys. Lett., 1994, 226, 517; (b) G. D. Reid, D. J. Whittaker, M. A. Day, C. M. Creely, E. M. Tuite, J. M. Kelly and G. S. Beddard, J. Am. Chem. Soc., 2001, 123, 6953.

49 Y. Kubota and R. F. Steiner, Biophys. Chem., 1977, 6, 279.

50 R. Ruiz, B. García, G. Ruisi, A. Silvestri and G. Barone, J. Mol. Struct: THEOCHEM, 2009, 915, 86.

51 (a) T. Maehigashi, O. Persil, N. V. Hud and L. D. Williams, RCSB Protein Databank ID 3FT6, DOI: 10.2210/pdb3ft6/pdb; (b) D. J. Patel and L. L. Canuel, Proc. Natl. Acad. Sci. USA, 1977, 74, 2624; (c) S. Neidle, A. Achari, G. L. Taylor, H. M. Berman, H. L. Carrell, J. P. Glusker and W. C. Stallings, Nature, 1977, 269, 304; (d) H.-S. Shieh, H. M. Berman, M. Dabrow and S. Neidle, Nucl. Acids Res., 1980, 8, 85; (e) B. Schneider, S. L. Ginell and H. M. Berman, Biophys. J., 1992, 63, 1572.

52 (a) A. H.-J. Wang, G. J. Quigley and A. Rich, Nucl. Acids Res., 1979, 6, 3879; (b) B. S. Reddy, T. P. Seshadri, T. D. Sakore and H. M. Sobell, J. Mol. Biol., 1979, 135, 787; (c) T. D. Sakore, K. K. Bhandary and H. M. Sobell, J. Biomol. Struct. Dyn., 1984, 1, 1219.

53 (a) P. Lincoln and B. Nordén, J. Phys. Chem. B, 1998, 102, 9583; (b) A. Reymer and B. Nordén, Chem Comm., 2012, 48, 4941.

54 (a) H.-K. Kim, P. Lincoln, B. Nordén and E. Tuite, Chem. Commun., 1997, 2375; (b) A. W. McKinley, P. Lincoln and E. M. Tuite, Dalton Trans., 2013, 42, 4081.

55 E. L. Gilroy, M. R. Hicks, D. J. Smith and A. Rodger, Analyst, 2011, 136, 4159.

56 H. Yamakawa and M. Fujii, Macromolecules, 1974, 7, 128. 